\title{
PROPRIEDADES DE FLUXO DE PARTICULADOS USADOS EM COMPOSIÇÕES POLIMÉRICAS ANTICHAMA
}

\author{
E. B. da $\operatorname{COSTA}^{1}$, R. A. da $\operatorname{COSTA}^{2}$, R. CONDOTTA ${ }^{1 *}$ \\ ${ }^{1}$ Centro Universitário da FEI, Departamento de Engenharia Química \\ ${ }^{2}$ Centro Universitário da FEI, Departamento de Engenharia de Materiais \\ *e-mail: rcondotta@fei.edu.br
}

\begin{abstract}
RESUMO
Cinco materiais particulados comerciais, Irganox ${ }^{\mathrm{TM}} 1010$ [antioxidante], Cloisite ${ }^{\mathrm{TM}} 20 \mathrm{~A}$ [argila organofílica], Surlyn ${ }^{\mathrm{TM}} 9420$ [EMMA-Zn $^{2+}$, Elvax ${ }^{\mathrm{TM}} 265$ [EVA] e Martinal ${ }^{\mathrm{TM}}$ OL104 $\left[\mathrm{Al}(\mathrm{OH})_{3}\right]$, foram propostos para preparação das pré-misturas antichama não halogenadas e foram caracterizados indivudualemente no reômetro de pó FT-4 dotado de uma célula de cisalhamento. O planejamento fatorial utilizado, $2^{2}+1$ ponto central com quatro pontos axiais, requereu a preparação de nove pré-misturas poliméricas, resultantes da combinação dos níveis de $\mathrm{R}_{1}$ (razão mássica entre SURLYNTM $9320 \mathrm{e}$ ELVAX $^{\mathrm{TM}} 265$ ) e $\mathrm{R}_{2}$ (razão mássica de $\mathrm{Al}(\mathrm{OH})_{3}$ e a fração polimérica total), sendo que a relação entre os demais constituintes (Cloisite 20A e Iraganox 1010) foi mantida constante e igual a 2. As propriedades de fluxo dos materiais particulados foram obtidas através de ensaios de cisalhamento para obtenção da linha de ruptura ("yield locus") em 4 níveis de consolidação distintos $(3,6,9$ e $15 \mathrm{kPa})$. O nível de significância (p) adotado foi igual a 0,05 para aplicação do teste de hipótese t-student. Todas as 9 prémisturas foram classificadas como coesivas segundo a sua função de fluxo, obtida a partir dos testes de cisalhamento, e uma expressão analítica para esta coesão foi obtida em função do ângulo de atrito interno. O ângulo de atrito interno das pré-misturas mostrouse ser independente da razão composicional $\mathrm{R}_{1}$ e dependente de $\mathrm{R}_{2}$, quando seus níveis foram mudados.
\end{abstract}

\section{INTRODUÇÃO}

A facilidade de processamento dos particulados sólidos em plantas industriais é fortemente dependente de suas propriedades de fluxo e, quando há dificuldades de escoamento, os processos se tornam ineficientes e de baixa produtividade. Além disso, os particulados sólidos tendem a se compactar em certas condições, durante a armazenagem e transporte, comprometendo seriamente as operações de transferência, alimentação de equipamentos e pode influenciar negativamente na qualidade do produto final (CARSON, TROXEL, BENGTSON, 2008).

Esses tipos de problemas são comuns para os particulados coesivos, exigindo projetos de equipamentos, apoiados nas suas características de fluxo, visando encontrar geometrias (ângulos e aberturas) que facilitam o escoamento de materiais particulados. Por essa razão, a caracterização das propriedades de fluxo de particulados sólidos é de suma importância para estudar condições que favoreçam o escoamento de particulados coesivos de forma uniforme, sem sofrer interferências significativas 
quando há paradas e retomadas do fluxo, durante o processamento.

A adição de baixas concentrações de nanopartículas e a modificação da coesão dos particulados através da alteração intencional de suas propriedades superficiais são possibilidades plausíveis para resolver alguns problemas de fluxo de particulados coesivos (KLAUSNER, CHEN, MEY, 2000).

Deste modo, o estudo e modelagem das propriedades de fluxo de particulados sólidos para projetos de equipamentos adequados, bem como a modificação das propriedades de superfície, são necessários para produzir fluxos altamente estáveis durante o processamento e operações de transferência que empregam este tipo de material. (LUMAY et al., 2012; FREEMAN, 2007).

Em função disto, decidiu-se investigar as propriedades de fluxo de pré-misturas precursoras de compósitos antichama que apresentam problemas de fluxo no funil de alimentação de extrusora de dupla de rosca, usadas para compostagem e granulação industrial de compósitos poliméricos antichama (RIBEIRO, FILHO, COSTA, 2002).

\section{METODOLOGIA}

Os materiais comerciais empregados na preparação das misturas são apresentados na Tabela 1.

Os dois copolímeros, Surlyn ${ }^{\mathrm{TM}} 9320$ e Elvax $^{\mathrm{TM}} 265$, foram submetidos à moagem criogênica com gelo seco, num moinho de facas (Marconi) dotado de uma tela de saída de $1,0 \mathrm{~mm}$. Todos os materiais particulados foram previamente secos em estufa a $40^{\circ} \mathrm{C}$ por 24 horas.

A composição das pré-misturas foi definida a partir do planejamento estatístico proposto - planejamento fatorial $2^{2}$ com 1 ponto central com quatro pontos axiais, representado geometricamente na Figura 1 para estudar a influência das variações composicionais dos particulados puros nas propriedades de fluxo destas pré-misturas. O planejamento utilizado apresenta dois recursos matemáticos importantes necessários para análise das propriedades de fluxos em relação às variações composicionais: $1^{\circ}$ ) permite avaliar se há ou não efeito não linear desta propriedade estudada quando os níveis das variáveis composicionais são mudados; e $2^{\circ}$ ) produz graus de liberdade para estimativa do erro padrão $( \pm \mathrm{EP})$ dos coeficientes dos polinômios com maior precisão, o que é importante quando se faz experimentos sem replicatas.

Tabela 1 - Materiais e suas funções e fabricantes.

\begin{tabular}{|c|c|c|c|}
\hline $\begin{array}{c}\text { Nome } \\
\text { Comercial }\end{array}$ & $\begin{array}{c}\text { Descrição } \\
\text { química usual }\end{array}$ & $\begin{array}{l}\text { Especificação } \\
\text { (função) }\end{array}$ & $\begin{array}{l}\text { Fabri- } \\
\text { cante }\end{array}$ \\
\hline ELVAXTM 265 & $\begin{array}{l}\text { Copolímero de } \\
\text { acetato de vinila e } \\
\text { etileno (EVA) }\end{array}$ & $\begin{array}{c}28 \% \text { de acetato de } \\
\text { vinila, } \mathrm{MFI}=2-3 \\
\text { g/10min. } \\
\text { (Matriz polimérica) }\end{array}$ & Du Pont \\
\hline $\begin{array}{l}\text { SURLYNTM } \\
9320\end{array}$ & $\begin{array}{l}\text { Copolímero do } \\
\text { ácido meta acrílico } \\
\text { e etileno } \\
\text { parcialmente } \\
\text { neutralizado. }\end{array}$ & $\begin{array}{c}\text { Grupos carboxilas } \\
\text { parcialmente } \\
\text { neutralizado com íons } \\
\text { Zn. } \\
\text { (Matriz polimérica, } \\
\text { compatibilizante) } \\
\end{array}$ & Du Pont \\
\hline $\begin{array}{l}\text { MARTINAL } \\
\text { TM OL104 }\end{array}$ & $\begin{array}{c}\text { Hidróxido de } \\
\text { Alumínio, } \mathrm{Al}(\mathrm{OH})_{3} \\
\text { ou Alumina } \\
\text { trihidradata } \\
\left(\mathrm{Al}_{2} \mathrm{O}_{3}\right) \cdot 3 \mathrm{H}_{2} 0\end{array}$ & $\begin{array}{c}\mathrm{D}_{50 \%} \text { (tamanho médio } \\
\text { de partículas) }=1,3- \\
2,3 \mu \mathrm{m} \\
\text { (Retardante de chama } \\
\text { ou antichama não } \\
\text { halogenado) } \\
\end{array}$ & $\begin{array}{l}\text { Martins- } \\
\text { weker } \\
\text { (Abermale } \\
\text { Corp.) }\end{array}$ \\
\hline $\begin{array}{c}\text { CLOISITE }^{\mathrm{TM}} \\
\text { 20A }\end{array}$ & $\begin{array}{c}\text { Montmorilonita } \\
\text { intercalada com } \\
\text { cloreto de dimetil } \\
\text { dialquil (derivado } \\
\text { do sebo) de } \\
\text { amônio. } \\
\end{array}$ & $\begin{array}{c}\text { Forma física: } \\
\text { organoargila em pó } \\
\text { Auxiliar de chama } \\
\text { (anti-escorrimento, } \\
\text { promotor de resíduo } \\
\text { carbonizado) }\end{array}$ & $\begin{array}{l}\text { Southern } \\
\text { Clay }\end{array}$ \\
\hline $\begin{array}{c}\text { IRGANOX }^{\mathrm{TM}} \\
1010\end{array}$ & $\begin{array}{l}\text { Antioxidante } \\
\text { fenólico estéreo- } \\
\text { impedido. }\end{array}$ & $\begin{array}{c}\text { Forma física }=\text { pó } \\
(\text { antioxidante para } \\
\text { minimizar a } \\
\text { degradação térmica da } \\
\text { matriz polimérica) }\end{array}$ & BASF \\
\hline
\end{tabular}

Figura 1 - Representação geométrica do arranjo ortogonal contendo um ponto central e quatro pontos axiais.

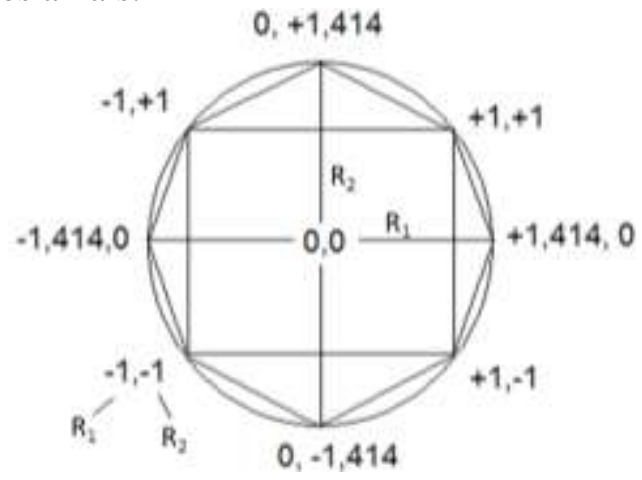

Fonte: BOX, HUNTER, HUNTER (1978) 
As duas variáveis independentes propostas neste estudo, correspondentes às duas proporções mássicas, foram: $\mathrm{R}_{1}=$ razão entre as frações mássicas de Elvax e Surlyn; e $\mathrm{R}_{2}=$ razão entre a fração de hidróxido de alumínio (Martinal) e a soma das frações poliméricas (Elvax e Surlyn). Uma terceira relação mássica entre Cloisite e Irganox foi mantida constante e igual a 2 , de modo a satisfazer o balanço mássico das composições. Os valores das composições codificados nos níveis do planejamento experimental e na forma de frações mássicas estão nas Tabelas 2 e 3, respectivamente.

Tabela 2 - Planejamento experimental.

\begin{tabular}{cccc}
\hline \multirow{2}{*}{ Formulação } & $\begin{array}{c}{[\text { SURLYN] }+[\text { ELVAX }} \\
{[\text { CLOISITE] }]+[\text { IRGANOX] }=1,5 \%}\end{array}$ \\
\hline \multirow{2}{*}{ Experimento } & \multicolumn{3}{c}{ Variáveis composicionais } \\
\cline { 2 - 4 } & $\mathrm{R}_{1}=\frac{\text { SURLYN }}{\text { ELVAX }}$ & $\mathrm{R}_{2}=\left(\frac{\text { MARTINAL }}{\text { ELVAX+SURLYN }}\right)$ & $\mathrm{R}_{3}=\frac{\text { CLOISITE }}{\text { IRGANOX }}$ \\
\hline 1 & $-1(0,125)$ & $-1(1.33)$ & 2 \\
2 & $+1(0,250)$ & $-1(1,33)$ & 2 \\
3 & $-1(0,125)$ & $+1(1,59)$ & 2 \\
4 & $+1(0,250)$ & $+1(1,59)$ & 2 \\
5 & $0(0,1875)$ & $0(1,46)$ & 2 \\
6 & $-\sqrt{2}(0,0991)$ & $0(1,46)$ & 2 \\
7 & $+\sqrt{2}(0,2759)$ & $0(1,46)$ & 2 \\
8 & $0(0,1875)$ & $-\sqrt{2}(1,2762)$ & 2 \\
9 & $0(0,1875)$ & $+\sqrt{2}(1,64)$ & 2 \\
\hline
\end{tabular}

Tabela 3 - Fração mássica das pré-misturas.

\begin{tabular}{cccccc}
\hline & \multicolumn{3}{c}{ Fração mássica percentual dos componentes de cada pré-mistura } \\
\cline { 2 - 6 } Exp. & SURLYN & ELVAX & MARTINAL & CLOISITE & IRGANOX \\
& 9320 & 265 & OL104 & 20A & 1010 \\
\hline 1 & 4,697 & 37,578 & 56,225 & 1,000 & 0,500 \\
2 & 8,455 & 33,820 & 56,225 & 1,000 & 0,500 \\
3 & 4,226 & 33,805 & 60,469 & 1,000 & 0,500 \\
4 & 7,606 & 30,425 & 60,469 & 1,000 & 0,500 \\
5 & 6,322 & 33,718 & 58,459 & 1,000 & 0,500 \\
6 & 3,610 & 36,430 & 58,459 & 1,000 & 0,500 \\
7 & 8,658 & 31,382 & 58,459 & 1,000 & 0,500 \\
8 & 6,833 & 36,441 & 55,226 & 1,000 & 0,500 \\
9 & 5,891 & 31,419 & 61,184 & 1,000 & 0,500 \\
\hline
\end{tabular}

Para a determinação das propriedades reológicas dos cinco particulados puros e das pré-misturas preparadas foi utilizada a célula de cisalhamento de um reômetro de pó FT4 (Freeman Technology Inc.) sob tensões de consolidação das amostras em 3, 6, 9 e $15 \mathrm{kPa}$.

As propriedades reológicas avaliadas a partir das envoltórias do círculo de Mohr, foram: coesão $(\mathrm{C})$, tensão de escoamento não confinado (UYS), tensão principal máxima (MPS), tensão de consolidação máxima
(MCS), ângulo de atrito interno (AIF), ângulo efetivo de atrito interno, (AEIF), e densidade compactação (CBD), sendo a função de fluxo (FF) determinada pela razão entre UYS e o MPS. A compressibilidade do material em termos da porcentagem de volume reduzido (\%CPS) também foi avaliada.

No tratamento estatístico dos dados experimentais, as propriedades de fluxo foram definidas como variáveis dependentes e os efeitos de cada variável independente e de suas possíveis interações foram avaliados a partir da análise dos coeficientes dos polinômios ortogonais ajustados. O nível de significância de cada coeficiente polinomial foi calculado e comparado ao valor prefixado para $p$ igual a 0,05, usando o teste de hipótese t-student (BOX, HUNTER, HUNTER, 1978).

O polinômio ajustado para uma dada propriedade da pré-mistura $(y)$ resultantes da combinação dos níveis composicionais de $\mathrm{R}_{1} \mathrm{e}$ $\mathrm{R}_{2}$ foi representado pela seguinte equação genérica (1):

$$
\begin{array}{r}
y=B_{0}+B_{1} R_{1}+B_{2} R_{2}+B_{12} R_{1} R_{2} \\
+B_{11} R_{1}^{2}+B_{22} R_{2}^{2}
\end{array}
$$

Os coeficientes da expressão genérica da cada propriedade de fluxo, e seus respectivos erros padrão $( \pm \mathrm{EP})$ foram determinados, através do processamento dos dados experimentais, no módulo de regressão múltipla, usando o programa Statistica 7.1. O grau de ajuste de cada polinômio foi verificado através do coeficiente de correlação múltiplo (análise de variância multivariada).

\section{RESULTADOS}

A coesão de cada material particulado usado na composição antichama proposta foi determinada individualmente, e os resultados dos testes de cisalhamento representados através de círculos de Mohr. 
A Figura 2 apresenta os dois círculos de Mohr: o maior, referente a tensão principal de consolidação (MPS), e o menor, referente a tensão de ruptura no estado não confinado (UYS), para o Martinal OL104 $\left(\mathrm{Al}(\mathrm{OH})_{3}\right)$, numa tensão de consolidação de $9 \mathrm{kPa}$. A coesão foi determinada pela extrapolação do "yield locus" (reta que tangencia os dois círculos de Mohr) na tensão normal igual a zero. Já a função de fluxo (FF) obtida para os cinco materiais comerciais puros é ilustrada pela Figura 3.

Figura 2 - Resultado do ensaio de cisalhamento do hidróxido de alumínio sob uma tensão de consolidação de $9 \mathrm{kPa}$.

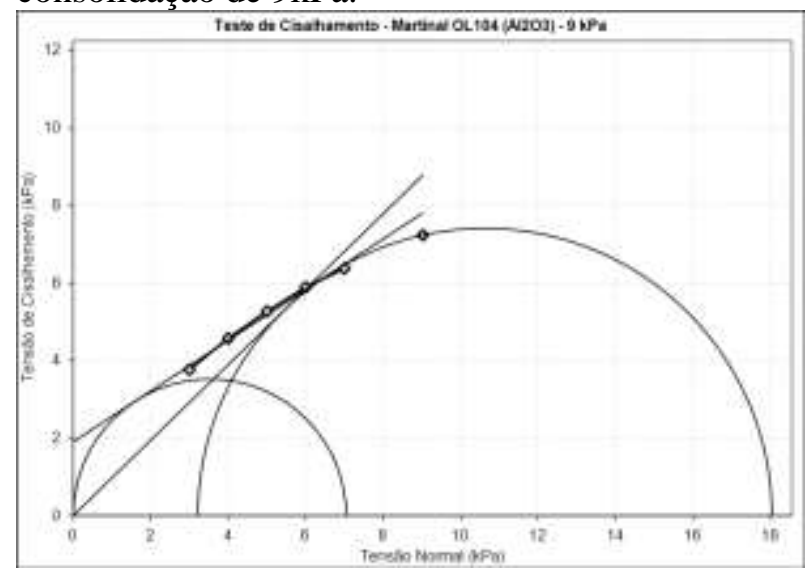

Figura 3 - Função de fluxo dos materiais comerciais puros.

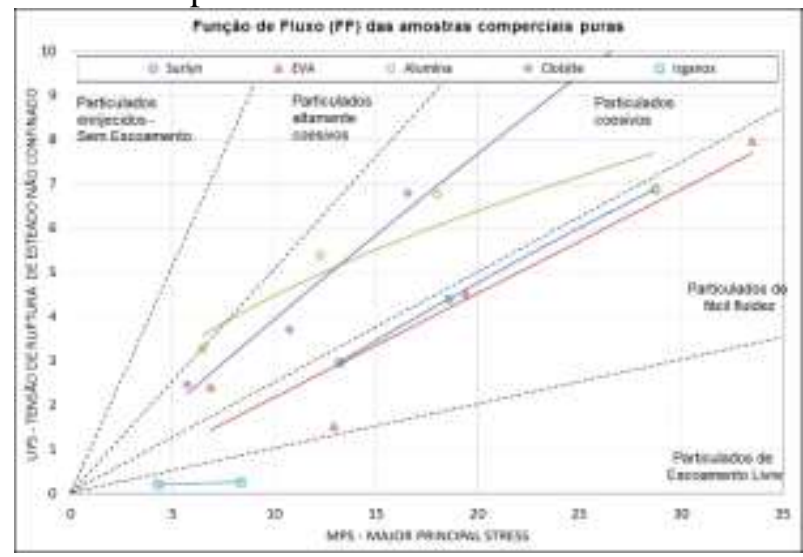

Analisando a função de fluxo dos componentes puros, observa-se que o Irganox é o componente de melhor fluidez, classificado como de fluxo livre, mas por se tratar do componente minoritário das pré-misturas $(0,5 \%)$, sua contribuição deve ser ínfima.

Por outro lado, a concentração de hidróxido de alumínio (Martinal) nas prémisturas é superior a $55 \%$ e por ser o componente majoritário, espera-se que sua influência nas propriedades de fluxo seja mais expressiva, se comparadas à dos demais componentes.

A fluidez do Martinal não é uma função linear da tensão normal sobre ele aplicada. Inicialmente, ele pode ser classificado como altamente coesivo a baixas tensões normais, e apresenta uma significativa melhora à medida que esta tensão aumenta. Já os demais materiais comerciais não sofrem qualquer alteração em sua aptidão ao escoamento com o aumento da tensão normal aplicada sobre eles, permanecendo sempre na mesma classificação quanto a sua fluidez independente da tensão normal sobre eles aplicada (Figura 3).

Conforme apresentado pela Figura 4, a função de fluxo das pré-misturas se mostrou dependente da tensão normal, comportamento típico do componente majoritário $\mathrm{Al}(\mathrm{OH})_{3}$ (Martinal), conforme previsto.

Assim, analisou-se a influência da tensão de consolidação no ângulo de atrito interno (AIF) e no ângulo efetivo de atrito interno (EAIF) e constatou-se que esta influência só é significativa para a coesão, mas apenas parcialmente, conforme a Figura 5.

Isto significa que os ângulos de atrito interno e efetivo são propriedades intrínsecas do material que além de depender das características dos particulados foram dependentes das variações composicionais $\left(\mathrm{R}_{1}, \mathrm{R}_{2}\right)$, como mostrado nas Figuras 6 e 7.

Assim sendo, analisando apenas as propriedades inerentes a composição das prémisturas através, chegou-se à conclusão que a tensão de ruptura do estado não confinado (UYS - unconfined yield stress) é função somente da coesão desenvolvida pelo material nos diferentes estados de consolidação, conforme ilustrado pela Figura 8. 
Figura 4 - Função de fluxo das pré-misturas

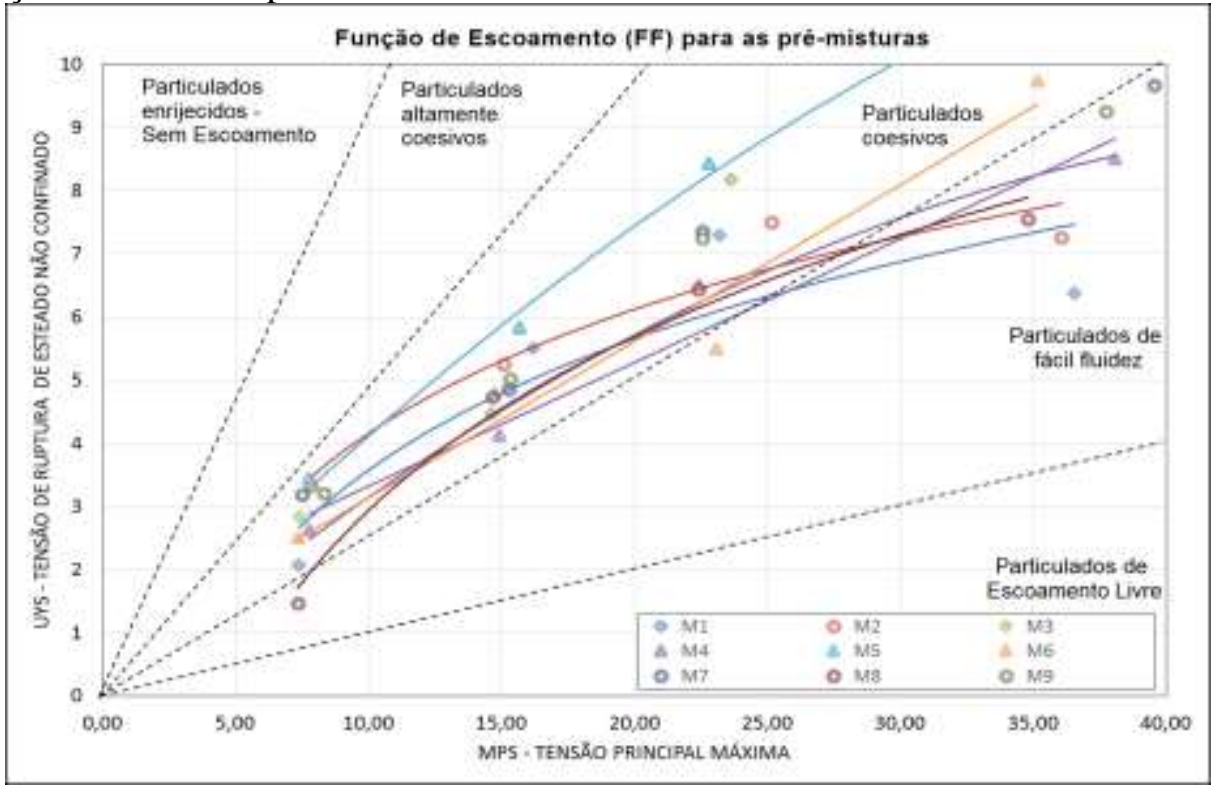

Figura 5 - Coesão desenvolvida pelas pré-misturas em função da tensão normal de consolidação.

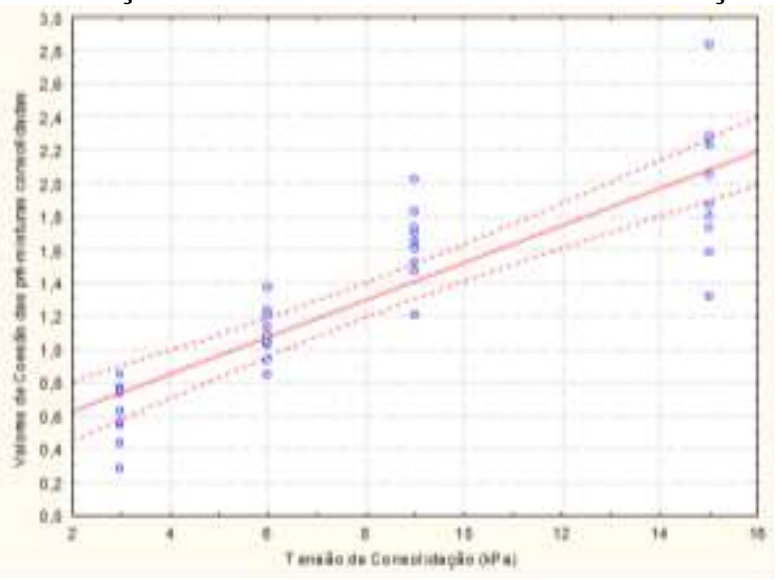

Figura 6 - Dependência do ângulo de atrito interno com a composição dada pela variável $R_{1}$.

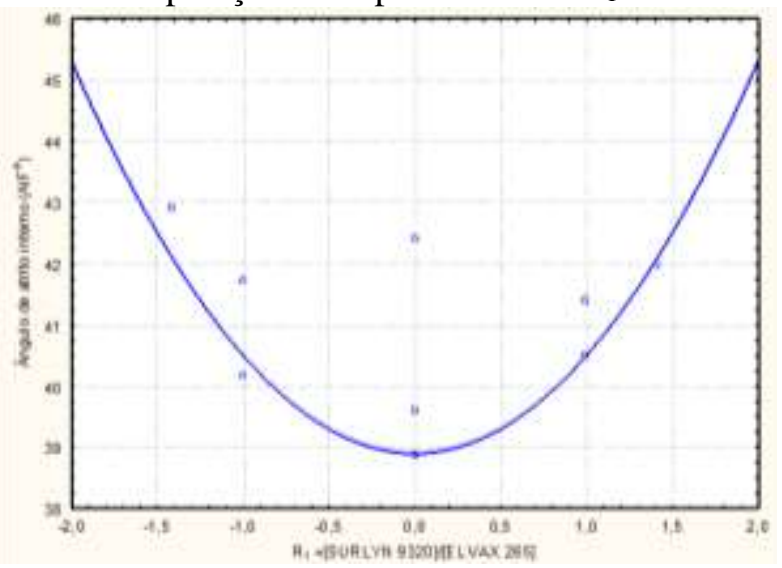

Figura 7 - Dependência do ângulo de atrito interno com a composição dada pela variável $\mathrm{R}_{2}$.

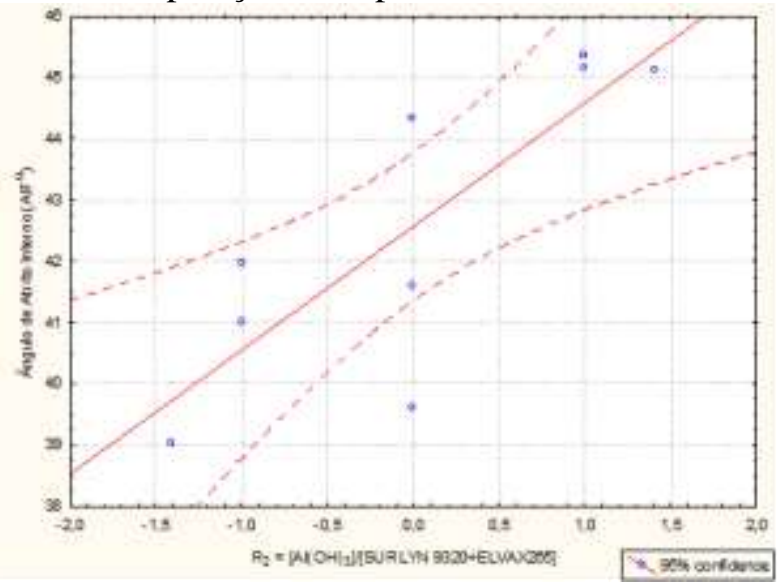

Figura 8 - UYS em função de coesão desenvolvida pelo material nos 4 estados de consolidação.

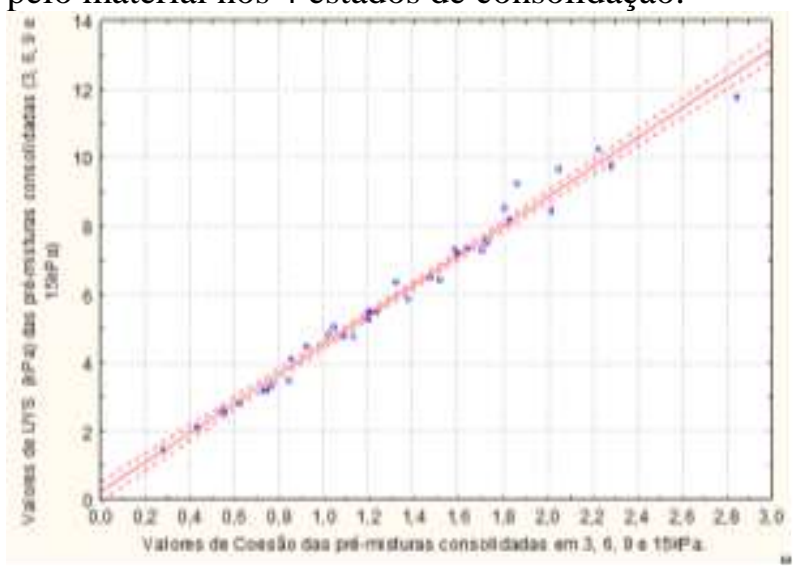


A partir dos dados experimentais apresentados na Figura 8, foi possível obter a Equação (2) para se estimar a tensão de ruptura no estado não confinado em função da coesão do material.

$$
U Y S[k P a]=4,3 \times \operatorname{Coesão}[k P a]
$$

Constatou-se ainda que a compressibilidade das pré-misturas também se mostrou dependente apenas do teor de hidróxido de alumínio (Martinal OL104) presente na composição, conforme ilustra a Figura 9.

Figura 9 - Dependência da compressibilidade das pré-misturas a $15 \mathrm{kPa}$ com a composição dada pela variável $\mathrm{R}_{2}$

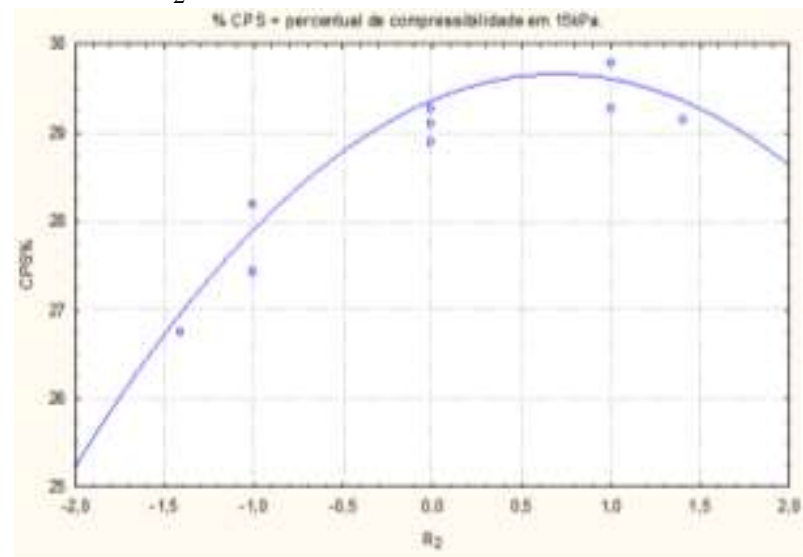

Assim, a partir dos resultados apresentados, conclui-se que as propriedades de fluxo das pré-misturas foram dependentes do teor de hidróxido de alumínio empregado e grande parte delas independeram da variação de $R_{1}$ e $R_{2}$, exceto os ângulos de atrito e a compressibilidade das pré-misturas, como mostrados nas Figuras 6, 7 e 9, respectivamente.

Finalmente, foi possível obter uma expressão capaz de relacionar a tensão de ruptura do estado não consolidado com a coesão do material, visto que os testes de cisalhamento permitem a estimativa destes dois parâmetros. Assim, esta correlação pode ser utilizada para se estimar a coesão de pré- misturas, de composição semelhante, no segmento industrial, a partir de testes uniaxial simples para a determinação da tensão de ruptura do estado não confinado, como o indicado por Schwedes (2002) e ilustrado pela Figura 10.

Figura 10 - Teste uniaxial.
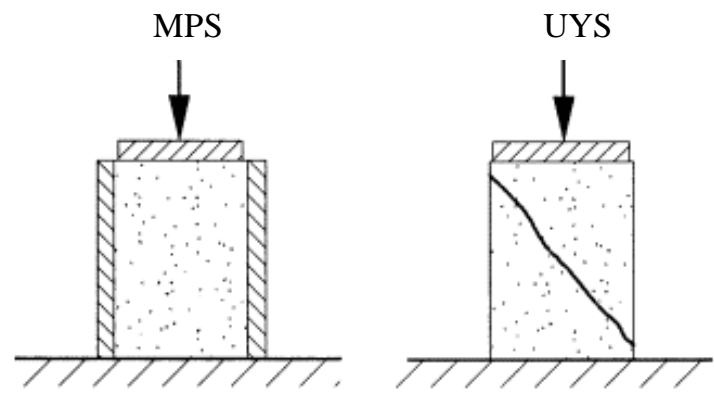

Fonte: Schwedes (2002)

\section{CONCLUSÕES}

Através do ensaio de cisalhamento foi possível determinar a coesão desenvolvida pelos diferentes materiais particulados em diferentes níveis de consolidação. Identificouse o hidróxido de alumínio como componente mais coesivo das pré-misturas que dificulta o escoamento das mesmas.

Conclui-se que as propriedades de fluxo das pré-misturas poliméricas antichamas não halogenadas foram dependentes do teor de hidróxido de alumínio (agente antichama) empregado, sendo este o material de menor fluidez, em relação aos demais componentes constituintes da pré-mistura antichama. As propriedades de fluxo das pré-misturas não foram influenciadas significativamente pelas variáveis de composições $\left(\mathrm{R}_{1}, \mathrm{R}_{2}\right)$, exceto os ângulos de atrito e a compressibilidade das prémisturas.

\section{REFERÊNCIAS}

BOX G.E.P., HUNTER W.G., HUNTER J.S. Statistics for Experimenters An Introdution to Design, Data Analysys and 
Model Building. New York:John Wiley \& Sons, 1978.

CARSON J.W., TROXEL T.G., BENGTSON K.E. Successfully scale up solids handling. Jenike \& Johanson, Inc., 2008.

FREEMAN R., Measuring the flow properties of consolidated, conditioned and aerated powders - A comparative study using a powder rheometer and a rotational shear cell. Powder Technology, v.174, p.25-33, 2007.

KLAUSNER J.F., CHEN D., MEI R. Experimental investigation of cohesive powder rheology. Powder Technology, v.112, p.94-101, 2000.

LUMAY G., BOSCHINI, R., TRAINA, K., BONTEMPI, S., REMY, J.-C., CLOOTS, R., VANDEWALLE, N. Measuring the flowing properties of powders and grains. Powder Technology. v.224, p.19-27, 2012.

RIBEIRO A. A., FILHO P. P. A., COSTA R. A. Processo de obtenção de hidróxido de magnésio a partir da magnesita. Patente BR PI0201597-8, 2002.

SCHWEDES, J. Consolidation and flow of cohesive bulk solids. Chemical Engineering Science v.57, p. 287-294, 2002. 